\title{
Assessment of the quality of life in patients on haemodialysis in Iraq
}

Safauldeen A. Alhajim ${ }^{\prime}$

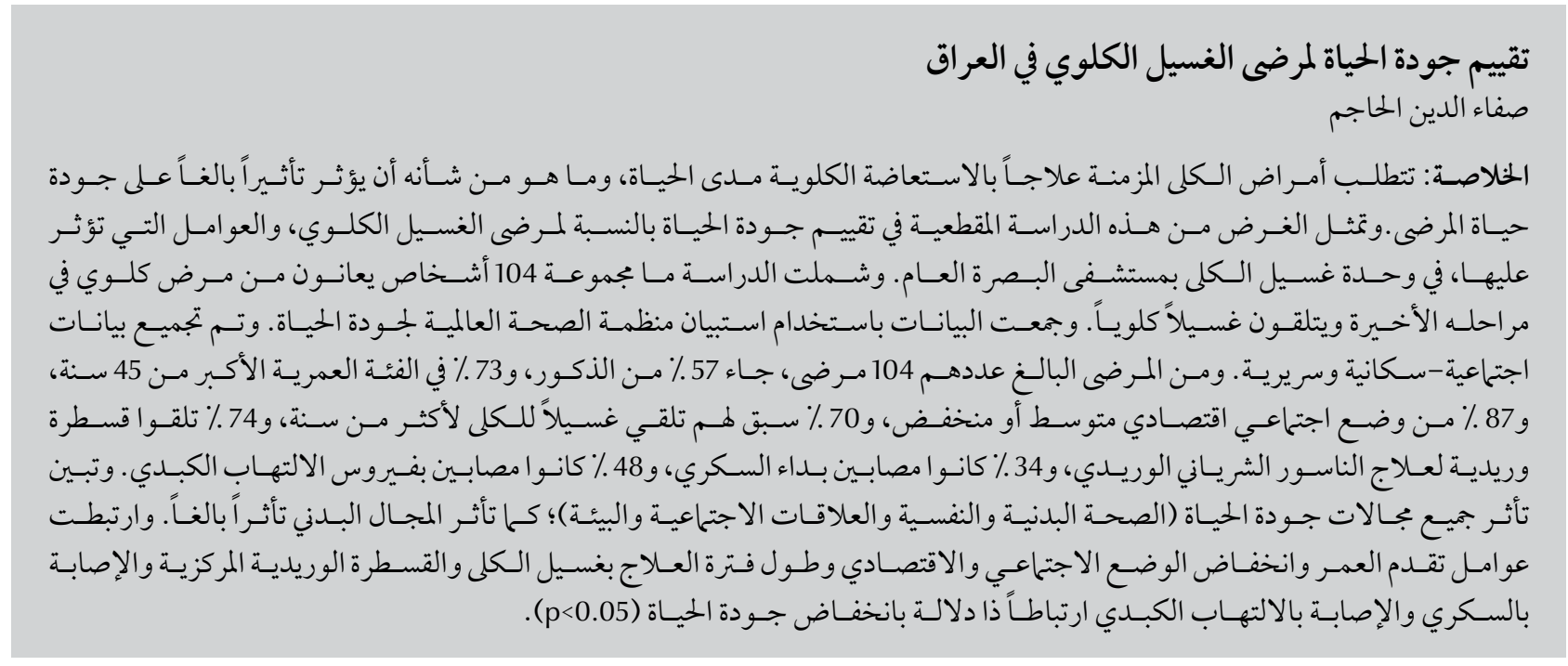

ABSTRACT Chronic kidney disease requires life-long renal replacement therapy, which can greatly impair the quality of life (QOL) of patients. This cross-sectional study aimed to assess the QOL of patients on haemodialysis, and the factors affecting it, at the dialysis unit of Basra General Hospital. A total of 104 patients with end-stage renal disease on haemodialysis were included. Data were collected using the World Health Organization QOL questionnaire. Sociodemographic and clinical data were also collected. Of the 104 patients, 57\% were male, 73\% were older than 45 years, $87 \%$ were of middle and low socioeconomic status, $70 \%$ had been on dialysis for more than 1 year, $74 \%$ had arteriovenous fistula vascular access, $34 \%$ had diabetes and $48 \%$ were positive for hepatitis virus. All domains of QOL (physical health, psychological, social relationships and environment) were affected; the physical domain was the most severely affected. Older age, lower socioeconomic status, longer duration of dialysis, central line vascular access, having diabetes and positive hepatitis serology were significantly associated with lower QOL $(\mathrm{P}<0.05)$.

\section{Évaluation de la qualité de vie des patients sous hémodialyse en Iraq}

RÉSUMÉ L'existence d'une maladie rénale chronique nécessite la mise en place d'une thérapie de remplacement rénal à vie, ce qui peut grandement impacter la qualité de vie des patients. La présente étude transversale avait pour objectif d'évaluer la qualité de vie des patients sous hémodialyse, ainsi que les facteurs de détérioration de la qualité de vie, à l'unité de dialyse de l'hôpital général de Bassora. Au total, 104 patients atteints de maladie rénale en phase terminale et sous hémodialyse ont été inclus à l'étude. Les données ont été collectées à l'aide du questionnaire d'évaluation de la qualité de vie de l'Organisation mondiale de la Santé. Des données sociodémographiques et cliniques ont également été recueillies. Sur les 104 patients, 57 \% étaient des hommes, $73 \%$ étaient âgés de plus de 45 ans, $87 \%$ étaient issus de milieux socio-économiques moyen et faible, $70 \%$ étaient sous dialyse depuis plus d'un an, $74 \%$ disposaient d'un abord vasculaire de type fistule artério-veineuse, $34 \%$ souffraient de diabète et $48 \%$ avaient contracté le virus de l'hépatite. Tous les domaines de la qualité de vie (santé physique, psychologique, relations sociales et environnement) étaient affectés, le domaine physique étant celui le plus impacté. Un âge plus avancé, un statut socio-économique inférieur, une durée prolongée de la dialyse, un abord vasculaire par cathéter central, le fait d'être diabétique et d'avoir une sérologie positive au virus de l'hépatite étaient associés de façon significative à une diminution de la qualité de vie $(p<0,05)$.

'Department of Medicine, College of Medicine, University of Basra, Basra, Iraq (Correspondence to: Safauldeen A. Alhajim: safauldinhachim@ yahoo.com).

Received: 28/12/15; accepted: 19/02/17 


\section{Introduction}

Chronic kidney disease affects 5-10\% of the world's population; it is associated with poor quality of life (QOL) and imposes a high economic burden (1-3). This is particularly true in the developing world where resources are limited (4). The global prevalence of end-stage renal disease, which is associated with considerable morbidity and mortality, has increased in the past 2 decades. The treatment option at this stage is renal replacement therapy, which includes dialysis and kidney transplant $(1,2)$. According to various studies, the cost of dialysis is between US\$ 3000 and 4000 per month, and it is a lifelong treatment. It is very difficult for the average patient to afford dialysis and it is important to ensure good QOL while on such expensive treatment (3).

The World Health Organization (WHO) has defined QOL as "an individual's perception of their position in life in the context of the culture and value systems in which they live and in relation to their goals, expectations, standards and concerns" (4). Many studies have evaluated QOL with generic as well as disease-specific instruments (5). The assessment of QOL is an essential element of health care evaluation and helps suggest suitable measures to be taken to increase the QOL of patients with end-stage renal disease.

Haemodialysis is not a cure for chronic kidney disease but helps to prolong and improve a patient's life (6). However, patients on haemodialysis often experience complications such as cardiovascular disease which decrease their QOL. Furthermore, comorbidities, such as anaemia, diabetes mellitus, hypertension, dyslipidaemia and thyroid disorders, greatly impair the QOL of patients on haemodialysis, negatively affecting their physical, social, financial and psychological well-being (7). Studies show that because of lack of awareness, patients often do not come for timely dialysis until severe comorbidities develop (8). Several studies have shown that regular pre-dialysis attendance helps to provide the patient with proper education and thereby achieve better QOL (9). These findings were supported by the study of Lii et al. who concluded that patients who received psychosocial interventions showed better QOL (10).

Improvement in the QOL has become the major treatment goal in end-stage renal disease patients (8). Therefore, the aim of this study was to evaluate the QOL of patients on haemodialysis in the dialysis unit of Basra General Hospital, Iraq.

\section{Methods}

\section{Study design and setting}

This was a cross-sectional study carried out at the dialysis unit of Basra General Hospital. This unit serves about $200 \mathrm{pa}-$ tients, providing an average of 3 dialysis sessions per week for each patient, free of charge.

\section{Study sample}

The sample was drawn from patients registered at the unit. The inclusion criteria were patients aged over 18 years who were diagnosed with end-stage renal disease and had completed at least 3 months on haemodialysis. Patients who declined to answer the questionnaire, those who had voluntarily withdrawn from dialysis, those with severe illness or psychosis, and pregnant and lactating women were excluded.

\section{Data collection}

Data were collected from April to October 2013 using a data collection form. It included information on: sociodemographic characteristics, principal diagnosis, co-morbid conditions

Transformed scale $=\left[\frac{(\text { Actual raw score }- \text { lowest possible raw score })}{\text { possible raw scrore range }}\right] \times 100$ (diabetes, hypertension and diabetes and other co-morbidities, such as polycystic kidney disease and systemic lupus erythematosus), type of vascular access [arteriovenous fistula (AV-fistula) or central line], duration of haemodialysis, and hepatitis serology status (hepatitis $\mathrm{B}$ and/or C positive, hepatitis B and C negative).

Data were collected by interview during the dialysis session. It took about 30 minutes for each patient. The interview questionnaire was tested on a small sample to assess any errors and bias that could occur in explaining questions and to avoid suggestions by the interviewer.

Patients were divided into 3 subgroups according to the duration of dialysis: group I were on dialysis for $<1$ year, group II for 1-3 years and group III for $>3$ years. Socioeconomic status of participating patients was categorized as upper, middle, and lower socioeconomic status based on income, educational level and type of employment (11).

To assess the quality of life we adapted the WHOQOL-BREF assessment questionnaire (short form of WHO-100), which has been used worldwide (4). This questionnaire has 26 items, which assess 4 main domains: physical health, psychological health, social relationships and environment of the patient. After recording all necessary items, a raw score is calculated for each facet and each domain. Both facet and domain are scored through simple summation of each item in that scale. Each question contributes equally to the facet score and each facet contributes equally to the domain score. Since each facet has 4 items with response value of 1 to 5, the raw score for any facet has a minimum value of 4 and a maximum value of 20. The next step involves transforming each raw scale score to a 0-100 scale using the formula below: 
where the actual raw score is the value reached by summation, the lowest possible raw score is the lowest possible value that could be reached by summation (this value would be 4 for all facets), and the possible raw score range is the difference between the maximum possible raw score and the lowest possible raw score, i.e. $20-4=16$ for all facets. This transformation converts the lowest and highest possible scores to zero and 100 , respectively.

\section{Statistical analysis}

Data obtained from the WHOQOL$B R E F$ questionnaire were analysed using SPSS, version 20.0. Descriptive analysis was done using mean and standard deviation (SD), and number and percentage of each value. The chisquared test was used to compare the effect of different variables on $\mathrm{QOL}$ scores A $P$-value less than 0.05 was considered statistically significant.

\section{Ethical considerations}

The study was approved by the ethics committee in Basra Medical College. Written informed consent was obtained from all the participants.

\section{Results}

A total of 104 patients met the inclusion criteria and were included in the study. Of these, 59 (57\%) were male. The mean age of the patients was 49.7 (SD 13.1) years. With regard to duration of dialysis, 31 (30\%) patients were on dialysis for $<1$ year, 40 (38\%) for $1-3$ years and $33(32 \%)$ for $>3$ years. Most patients, 77 (74\%), had AV-fistula access and $27(26 \%)$ had central line access. Out of the 104 patients, 35 (34\%) had diabetes, $23(22 \%)$ had hypertension and diabetes, while the remaining 46 (44\%) had other co-morbidities such as polycystic kidney disease and systemic lupus erythematosus. With regard to socioeconomic status of the participating patients, 13 (13\%) were categorized as upper socioeconomic status, 44 (42\%) as middle and $47(45 \%)$ as lower socioeconomic status. Regarding the hepatitis serology status, 50 (48\%) patients were positive for hepatitis virus and $54(52 \%)$ were negative.

The overall QOL of patients on haemodialysis was greatly impaired: the mean (SD) score was 39.1 (16.1). The QOL of 58 (56\%) patients was greatly affected (score < 50), while $46(44 \%)$ patients were mildly affected (score $\geq$ 50).

Table 1 shows effect of the studied variables on the QOL of the patients. There was no significant effect of the patient's gender on the QOL $(P=0.969)$. However, older age $(P=0.004)$, longer duration of dialysis $(P=0.001)$, having central line vascular access $(P=0.002)$, having diabetes and hypertension, or diabetes co-morbidity $(P=0.001)$, lower socioeconomic status $(P=0.003)$, and positive hepatitis serology $(P=0.0001)$ all negatively affected QOL (Table 1 ).

The transformed scores of the 4 main domains of QOL were: physical (34\%), psychological (40\%), environmental (48\%) and social (53\%).

\section{Discussion}

This study found that the quality of life of patients on haemodialysis was significantly impaired. A similar effect on QOL was observed in other studies $(12,13)$.

Common complications of dialysis, such as strict dietary restrictions, reduce social and recreational activities. Medical complications, economic pressure, marital disputes, sexual dysfunction, emotional stress and anxiety result in further pressure on patients and their caregivers that impair their QOL. Moreover, daily activities are also affected by renal failure, including sleeping, eating, working and planning a daily schedule, and these can become a challenge for patients and their families. Many permanent changes in family roles and expectations are needed for patients with end-stage renal disease, which can also increase the stress level and decrease QOL (14). In addition, caregivers also face many difficulties, such as changes in sleep patterns, health and social activities (15). In addition, patients have to spend at least 3 days a week on dialysis, often accompanied by their caregivers, which imposes limitations on social life and creates a feeling of dependency on the dialysis centre. So, both patients and caregivers have to make many modifications to their life styles (16).

The present study showed that the physical domain of QOL was the most affected, followed by psychological, environmental and social domains. Similar results have been reported in other studies (17,18).

According to various studies, male patients with end-stage renal disease outnumber female patients. This may be because of the smoking and alcohol habits of men, which might aggravate renal failure $(8,19)$. However, in the presentstudy, there was no significant effect of gender on QOL, which is similar to a study from Egypt (20).

Older patient age was negatively associated with QOL in our study, mainly in the physical domain. This finding is in line with several studies that showed similar results $(21-24)$. The negative effect of the disease process on the physical activity of patients, such as a decrease in haematocrit, and musculoskeletal and neurological problems may contribute to this finding. Because of a physiological decline from ageing, the elderly experience a gradual and progressive reduction in their functional capacity. This may limit their daily activities and result in worse QOL for dimensions associated with physical health (25).

The duration of dialysis adversely affects QOL in dialysis patients and was significantly associated with lower QOL in the patients in the present 


\begin{tabular}{|c|c|c|c|}
\hline \multirow[t]{3}{*}{ Variable } & \multicolumn{2}{|c|}{ Quality of life } & \multirow[t]{3}{*}{$P$-value } \\
\hline & Badly affected & Mildly affected & \\
\hline & No. (\%) & No. (\%) & \\
\hline Sex & & & 0.969 \\
\hline Male & $33(56)$ & $26(44)$ & \\
\hline Female & $25(56)$ & $20(44)$ & \\
\hline Age (years) & & & 0.004 \\
\hline $18-45$ & $9(32)$ & $19(68)$ & \\
\hline$>45$ & $49(64)$ & $27(36)$ & \\
\hline Duration of dialysis (years) & & & 0.001 \\
\hline$<1$ & $9(29)$ & $22(71)$ & \\
\hline $1-3$ & $25(62)$ & $15(38)$ & \\
\hline$>3$ & $24(73)$ & $9(27)$ & \\
\hline Vascular access & & & 0.002 \\
\hline Arteriovenous fistula & $36(47)$ & $41(53)$ & \\
\hline Central line & $22(81)$ & $5(19)$ & \\
\hline Co-morbidities & & & 0.001 \\
\hline Diabetes & $22(63)$ & $13(37)$ & \\
\hline Diabetes and hypertension & $19(83)$ & $4(17)$ & \\
\hline Other & $17(37)$ & $29(63)$ & \\
\hline Socioeconomic status & & & 0.003 \\
\hline Upper & $2(15)$ & $11(85)$ & \\
\hline Middle & $18(41)$ & $26(59)$ & \\
\hline Lower & $40(85)$ & $7(15)$ & \\
\hline Hepatitis serology & & & 0.0001 \\
\hline Negative & $11(20)$ & $43(80)$ & \\
\hline Positive & $47(94)$ & $3(6)$ & \\
\hline
\end{tabular}

study. QOL was better in patients with a haemodialysis duration of less than 1 year compared with patients with a dialysis duration 1-3 years, and both groups had a better QOL than those on dialysis for more than 3 years. Initially, when patients start dialysis, they may think that their kidneys will recover and dialysis will be stopped, but with the passage of time when they maintain their life on dialysis, their worries increase and impair their QOL. A similar observation has been made in another study in which QOL remained constant during the first year of dialysis (26).

AV-fistula is considered the best form of vascular access for those who have end-stage renal disease and receive haemodialysis. The clinical practice guidelines for vascular access of the
National Kidney Foundation's Kidney Disease Outcomes Quality Initiative recommend early placement and use of an AV-fistula in at least 50\% of incident patients on haemodialysis (27). Referral of pre-dialysis patients to nephrologists is usually late and a temporary access catheter is used as the primary access for dialysis. A study in Pakistan reported late referral in 100\% of dialysis patients and temporary access catheter was used for dialysis in these patients (28). Failure of AV-fistula in dialysis patients also contributes to the use of central lines. When catheters are used as the primary access for dialysis, they affect not only QOL but also morbidity because they are a continuous source of infection in the body. Furthermore, the inconvenient site of central lines may make daily activities like bathing and sleeping more difficult, and they may be socially embarrassing and cosmetically unaccepted (21). In this study, central line access for haemodialysis adversely affected the QOL of the patients.

The main cause of end-stage renal disease in this study was diabetes mellitus, which is similar to other national and international studies $(28,29)$. In the present study, the QOL of diabetic patients on dialysis was poor compared with patients without diabetes. Diabetes affects multiple organs in the body; it affects the eyes causing vision problems, and leads to cardiac problems, kidney failure, cerebrovascular events and peripheral vascular disease, which may result in amputation and impaired QOL. All these problems limit daily 
activities and work capacity, lead to dependence on anti-diabetes drugs and disturbed sleep because of pain which affects physical health. A similar pattern of poor QOL has been reported in other studies (30,31). Furthermore, in the present study, QOL was markedly affected in patients with concomitant diabetes and hypertension compared with patients with diabetes alone because of the additional complications imposed by hypertension.

Socioeconomic status was also significantly associated with QOL in the present study; those of lower socioeconomic status had a lower QOL. The findings of other studies, which found that employed patients had a better QOL than unemployed patients, support this finding $(12,22)$. Demographic factors such as unemployment, low education and low socioeconomic status can impair QOL (32). This is because financial independence may improve QOL in working patient to some extent. Also, daily activity and work capacity may help to improve QOL (12). Holding down a job certainly has a positive influence on the perception that an individual has a role in society and it contributes to improved self-esteem, which is an important aspect of QOL (24). Higher education also raises the QOL according to a study from Italy (33), and can raise awareness of chronic diseases and help patients acquire better coping skills (24).

The QOL in haemodialysis patients with positive hepatitis serology was significantly impaired which may be due to multiple factors such as social isolation, sexual deprivation and the development of clinical features and complications of hepatitis itself (24).

The main limitation of our study was the relatively small patient sample. We studied the correlation of QOL with dialysis-related factors and there is a need for further study of healthrelated domains of QOL in a much larger sample of patients with end-stage renal disease. The QOL questionnaire was completed when patients came for dialysis, where they may feel more secure and friendly to dialysis staff, which may affects their how they are feeling and hence their responses when interviewed.

\section{Conclusion}

The results of the present study provide evidence that the QOL of the haemodialysis patients is significantly impaired. Gender had no significant effect on QOL. Increasing age, longer duration of dialysis, diabetes and hypertension, central venous catheter as a vascular access for dialysis, lower socioeconomic status, and positive hepatitis serology were all statistically significant factors that adversely affected QOL. Some of these factors are modifiable, so we should aim for better diabetes and hypertension control, encourage the use of AV-fistula rather than central catheter, and improve infection control for hepatitis viruses.

\section{Acknowledgement}

I would like to acknowledge Dr Safaa A. Hneid for his help in the collection of the data for this study.

\section{Funding: None.}

Competing interests: None declared.

\section{References}

1. De Nicola L, Zoccali C. Chronic kidney disease prevalence in the general population: heterogeneity and concerns. Nephrol Dial Transplant. 2016 Mar;31(3):331-5. https://doi. org/10.1093/ndt/gfv427 PMID:26908831

2. Prabahar MR, Chandrasekaran V, Soundararajan P. Epidemic of chronic kidney disease in India -what can be done? Saudi J Kidney Dis Transpl. 2008 Sep;19(5):847-53. PMID:18711313

3. Mani MK. The management of end-stage renal disease in India. Artif Organs. 1998 Mar;22(3):182-6. https://doi.org/10.1046/ j.1525-1594.1998.06070.x PMID:9527276

4. World Health Organization. WHOQOL-BREF. Introduction administration, scoring and generic version of the assessment. Field trial version. December 1996 (http://www.who.int/ mental_health/media/en/76.pdf, accessed 17 January 2018).

5. Germin-Petrović D, Mesaros-Devcić I, Lesac A, Mandić M, Soldatić M, Vezmar D, et al. Health-related quality of life in the patients on maintenance hemodialysis: the analysis of demographic and clinical factors. Coll Antropol. 2011 Sep;35(3):68793. PMID:22053542

6. Saban KL, Stroupe KT, Bryant FB, Reda DJ, Browning MM, Hynes DM. Comparison of health-related quality of life measures for chronic renal failure: quality of well-being scale, short-form-6D, and the kidney disease quality of life instrument. Qual Life Res. 2008 Oct;17(8):1103-15. https://doi. org/10.1007/s11136-008-9387-5 PMID:18791810
7. Christensen AJ, Ehlers SL. Psychological factors in end-stage renal disease: an emerging context for behavioral medicine research. J Consult Clin Psychol. 2002 Jun;70(3):712-24. https:// doi.org/10.1037/0022-006X.70.3.712 PMID:12090378

8. Zhang AH, Cheng LT, Zhu N, Sun LH, Wang T. Comparison of quality of life and causes of hospitalization between hemodialysis and peritoneal dialysis patients in China. Health Qual Life Outcomes. 200708 2;5:49. PMID:17678543

9. White CA, Pilkey RM, Lam M, Holland DC. Pre-dialysis clinic attendance improves quality of life among hemodialysis patients. BMC Nephrol. 2002 04 5;3:3. PMID:11934351

10. Lii YC, Tsay SL, Wang TJ. Group intervention to improve quality of life in haemodialysis patients. J Clin Nurs. 2007 Nov;16(11c) 11C:268-75. https://doi.org/10.1111/j.1365-2702.2007.01963.x PMID:17931320

11. Holyachi SK, Santosh A. Socioeconomic status scales - an update. Ann Community Health. 2013;1:24-7.

12. Sathvik BS, Parthasarathi G, Narahari MG, Gurudev KC. An assessment of the quality of life in hemodialysis patients using the WHOQOL-BREF questionnaire. Indian J Nephrol. 2008 Oct;18(4):141-9. https://doi.org/10.4103/0971-4065.45288 PMID:20142925 
13. Vasilieva IA. Quality of life in chronic hemodialysis patients in Russia. Hemodial Int. 2006 Jul;10(3):274-8. https://doi. org/10.1111/j.1542-4758.2006.00108.x PMID:16805889

14. Arslanian J, Binkley L, Hudson S, Hudson M, Kammerer J, Levin $\mathrm{N}$, et al. Core curriculum for dialysis technicians. USA: Amgen Inc.; 1992.

15. Fast J, Keating N. Informal caregivers in Canada: A snapshot. Report to the Health Services Division. Edmonton: University of Alberta; 2001.

16. Sezer MT, Eren I, Ozcankaya R, Civi I, Erturk J, Ozturk M. Psychological symptoms are greater in caregivers of patients on hemodialysis than those of peritoneal dialysis. Hemodial Int. 2003 Oct 1;7(4):332-7. https://doi.org/10.1046/j.14927535.2003.00058.x PMID:19379384

17. Park HC, Yoon HB, Son MJ, Jung ES, Joo KW, Chin HJ, et al. Depression and health-related quality of life in maintenance hemodialysis patients. Clin Nephrol. 2010 May;73(5):374-80. https://doi.org/10.5414/CNP73374 PMID:20420798

18. Merkus MP, Jager KJ, Dekker FW, De Haan RJ, Boeschoten EW, Krediet RT; NECOSAD Study Group. Quality of life over time in dialysis: the Netherlands Cooperative Study on the Adequacy of Dialysis. Kidney Int. 1999 Aug;56(2):720-8. https://doi. org/10.1046/j.1523-1755.1999.00563.x PMID:10432414

19. Abdel-Kader K, Myaskovsky L, Karpov I, Shah J, Hess R, Dew $M A$, et al. Individual quality of life in chronic kidney disease: influence of age and dialysis modality. Clin J Am Soc Nephrol. 2009 Apr;4(4):711-8. https://doi.org/10.2215/CJN.05191008 PMID:19339411

20. Assal H, Emam $\mathrm{H}$, Abd El-Ghaffar N. Health related quality of life among Egyptian patients on haemodialysis. J Med Sci. 2006;6(3):314-20. https://doi.org/10.3923/jms.2006.314.320

21. Mittal SK, Ahern L, Flaster E, Maesaka JK, Fishbane S. Self-assessed physical and mental function of haemodialysis patients. Nephrol Dial Transplant. 2001 Jul;16(7):1387-94. https://doi. org/10.1093/ndt/16.7.1387 PMID:11427630

22. Frank A, Auslander GK, Weissgarten J. Quality of life of patients with end-stage renal disease at various stages of the illness. Soc Work Health Care. 2004;38(2):1-27. https://doi.org/10.1300/ J010v38n02_01 PMID:15022732

23. Sabbah I, Drouby N, Sabbah S, Retel-Rude N, Mercier M. Quality of life in rural and urban populations in Lebanon using SF-36 health survey. Health Qual Life Outcomes. 200308 6;1(1):30. https://doi.org/10.1186/1477-7525-1-30 PMID:12952543

24. Bohlke M, Nunes DL, Marini SS, Kitamura C, Andrade M, VonGysel MP. Predictors of quality of life among patients on dialy- sis in southern Brazil. Sao Paulo Med J. 2008 Sep;126(5):252-6. https://doi.org/10.1590/S1516-31802008000500002 PMID:19099157

25. Kusumoto L, Marques S, Haas V, Rodrigues RAP. Adult and elderly on haemodialysis evaluation of health related quality of life. Acta Paul Enferm. 2008;21:152-9. https://doi.org/10.1590/ S0103-21002008000500003

26. Hallinen T, Soini EJ, Martikainen JA, Ikäheimo R, Ryynänen OP. Costs and quality of life effects of the first year of renal replacement therapy in one Finnish treatment centre. J Med Econ. 2009 Jun;12(2):136-40. https://doi.org/10.3111/13696990903119530 PMID:19566482

27. KDOQI Clinical practice guideline for hemodialysis adequacy: 2015 update. Am J Kidney Dis. 2015 Nov;66(5):884-930. https://doi.org/10.1053/j.ajkd.2015.07.015 PMID:26498416

28. Anees M, Mumtaz A, Nazir M, Ibrahim M, Rizwan SM, Kausar T. Referral pattern fof hemodialysis patients to nephrologists. J Coll Physicians Surg Pak. 2007 Nov;17(11):671-4. PMID:18070574

29. United States Renal Data System. USRDS 2007 Annual Data Report. Bethesda (MD): National Institute of Diabetes and Digestive and Kidney Diseases, National Institutes of Health, US Department of Health and Human Services; 2007.

30. Gumprecht J, Zelobowska K, Gosek K, Zywiec J, Adamski M, Grzeszczak W. Quality of life among diabetic and nondiabetic patients on maintenance haemodialysis. Exp Clin Endocrinol Diabetes. 2010 Mar;118(3):205-8. https://doi. org/10.1055/s-0029-1192023 PMID:19226477

31. Sørensen VR, Mathiesen ER, Watt T, Bjorner JB, Andersen $M V$, Feldt-Rasmussen B. Diabetic patients treated with dialysis: complications and quality of life. Diabetologia. 2007 Nov;50(11):2254-62. https://doi.org/10.1007/s00125-0070810-1 PMID:17876568

32. Kalender B, Ozdemir AC, Dervisoglu E, Ozdemir O. Quality of life in chronic kidney disease: effects of treatment modality, depression, malnutrition and inflammation. Int J Clin Pract. 2007 Apr;61(4):569-76. https://doi.org/10.1111/j.17421241.2006.01251.x PMID:17263698

33. Mingardi G, Cornalba L, Cortinovis E, Ruggiata R, Mosconi P, Apolone G; DIA-QOL Group. Health-related quality of life in dialysis patients. A report from an Italian study using the SF-36 Health Survey. Nephrol Dial Transplant. 1999 Jun;14(6):150310. https://doi.org/10.1093/ndt/14.6.1503 PMID:10383015 